\title{
Modelling Conceptual Framework for Private Cloud Infrastructure Deployment in the ICT Centre of Tertiary Institutions
}

\author{
Emmanuel N. Ekwonwune ${ }^{1}$, Chukwuma D. Anyiam², Oliver E. Osuagwu ${ }^{1}$ \\ ${ }^{1}$ Deparment of Computer Science, Imo State University, Owerri, Nigeria \\ ${ }^{2}$ Deparment of Computer Science, Imo State Polytechnic, Umuagwo, Nigeria \\ Email: ekwonwuneemmanuel@yahoo.com
}

How to cite this paper: Ekwonwune, E.N., Anyiam, C.D. and Osuagwu, O.E. (2018) Modelling Conceptual Framework for Private Cloud Infrastructure Deployment in the ICT Centre of Tertiary Institutions. Communications and Network, 10, 117-125. https://doi.org/10.4236/cn.2018.103010

Received: February 12, 2018

Accepted: August 27, 2018

Published: August 30, 2018

Copyright $\odot 2018$ by authors and Scientific Research Publishing Inc. This work is licensed under the Creative Commons Attribution International License (CC BY 4.0).

http://creativecommons.org/licenses/by/4.0/

\begin{abstract}
This research work aims at modelling a framework for Private Cloud infrastructure Deployment for Information and Communication Technology Centres (ICTs) in tertiary institutions in Nigeria. Recent researches have indicated that cloud computing will become the mainstream in computing technology and very effective for businesses. All Tertiary Institutions have ICT units, and are generally charged with the responsibilities of deploying ICT infrastructure and services for administration, teaching, research and learning in higher institution at large. The Structured System Analysis and Design Methodology (SSADM) is used in this research and a six-step framework for a cost effective and scalable Private cloud infrastructure using server virtualization is presented as an alternative that can guarantee total and independent control of data flow in the institutions, while ensuring adequate security of vital information.
\end{abstract}

\section{Keywords}

Framework, Virtualization, Private Cloud, ICT Centres, Infrastructure

\section{Introduction}

The national policy on Information Technology Federal Republic of Nigeria (2004) envisaged the integration of Information and Communication Technology (ICT) at all levels of educational institutions. This was to play a leading role in the actualization of the goals of education as stated in the national policy on education. The goals include the contribution to national development through high manpower training, development of individual intellectual capability in 
order to understand their immediate environment, provision of opportunities for the acquisition of physical and intellectual skills for individuals to be self-reliant and useful members of the society to which they belong, etc. The Policy on ICT identified ICT as the bedrock of national survival and development in a rapidly changing global environment. ICT is an umbrella term that includes communication devises or application (radio, television, cellular phone, Computer hardware/Software, networking, and satellite system) and services associated with them. In addition, ICT is a term used to denote a wide range of services, application and technologies using various types of equipment and software running over telecommunication networks [1].

Cloud computing is a construct that allows you to access applications that actually reside at a location other than your computer or other internet connected devices, most often this may be a distant data centre [2]. There are many benefits to this. Prior to this time, the practice was for the Analyst who wants to install Microsoft Word, to purchase it, and would run around with the CD or DVD and installed it in all the computers in the organization/institution or he would setup the software distribution server to automatically install the application in the other systems. More so, every time Microsoft issues a Service Pack, the analyst would go round to install same or setup his software distribution server to distribute it [2]. Today Cloud technology is a proven delivery model, with a growing number of enterprises realizing impressive agility and efficiency benefits. There is an increasing perceived vision that cloud computing will make computing the fifth utility after water, electricity, gas, and telephone that will provide the basic level of computing services considered essential for fulfilling daily life routines [3]. In addition, as a growing technology, the trend is for organizations to extend cloud deployment to even more flexible private, hybrid and public cloud models that promise exciting ways to expand the scope of value added business services. Why Private Cloud? Awosan, (2014) [4] pointed out in his research several factors militating against public cloud computing in Nigeria. A private cloud offers the key advantages of Speed, agility, and efficiency while maintaining control of sensitive workloads [5]. Also according to Intel's, Private Cloud enables IT to be more responsive to business and to work more effectively with its constituencies. Private Cloud is referred to as internal cloud, which is exclusive to the internal use of an organization itself or managed by a third party [6]. Server virtualization is an IT modernization catalyst that will change how IT is acquired, consumed, managed, sourced and paid for [2]. Virtualization can apply to applications, servers, storage, and networks and is the single, most effective way to reduce IT expenses while boosting efficiency and agility for all size of businesses.

\section{Aim and Objectives}

The major objective of this research work is to model a conceptual framework for the deployment of a Private Cloud Infrastructure in the ICT centres of Terti- 
ary Institutions in Nigeria.

\section{Related Works}

In the study "A Phase Approach for Adopting Private Clouds as a Collaborative Platform for Nigerian Universities" by [7]. The study proposed a strategy for the adoption of Private Cloud model that will serve as a platform for collaboration among the Universities in Nigeria. While affirming that the dedicated nature of Private cloud would resolve the technical challenges with the public cloud, proposed a private cloud computing platform that has five layers namely Application, Software environment, Software Infrastructure, Software Kernel, and Hardware. This work dwelt more on the collaborative approach by Universities to deploying Private Cloud model.

In the research Cloud Computing Framework for Ethiopian Higher Education Institutions proposed the implementation of a central hybrid cloud computing infrastructure that combines both the current local infrastructure of the universities as the private cloud and public cloud to enable the sharing of educational resources and collaboration within all universities in Ethiopia and the global educational community, so that Ethiopian higher institutions can enjoy the benefits of ICT in an efficient and affordable way [8]. The research further states that by deploying the proposed hybrid cloud model, the risks of privacy and other security challenges can be avoided as critical and sensitive data will be housed in a private cloud.

In the study Cloud Computing Adoption Model for Universities to Increase ICT Proficiency by [3], the study affirms that cloud adoption and usage has come to stay. In addition the study also concurs that the University ICT department (IT department) oversees the deployment, running and maintenance of all IT programs and projects. Therefore, to get the best of the cloud technology paradigm, the article proposes a cloud computing adoption model, which consists of the following: Strategic guidelines to overcome security and privacy concerns, Strategic guidelines to overcome reliability concerns of the Cloud Service Providers, and a roadmap for the successful adoption of cloud computing. This roadmap has seven stages namely planning, choosing the right deployment model, choosing the most suitable service models, vendor selection, negotiating the SLA, migration, and integration. The study adopted the hybrid deployment model as the cloud deployment model of choice for Universities.

These researchers all agreed that Private Cloud infrastructure would give the Universities control and resolve the technical challenges with public cloud. However the works did not discuss the role of the ICT centres as key player in actualizing the task being the particular unit that would manage and maintain such infrastructure in the campuses.

\section{Research Methodology}

This work follows the Structured System Analysis and Design Methodology 
(SSADM) because it offers a systematic sequence of breaking / decoupling a complex system into simpler parts such that a solution can be proffered sequentially. Cloud Computing is a very complex system, and proposing a Private Cloud Infrastructure is even more complex system. Therefore, using SSADM the components namely Problem Identification, Feasibility Study, System Analysis, Design, Implementation and testing were followed. In addition, Prototyping as a methodology was also employed in this study.

\subsection{System Analysis}

All higher institutions have ICT units located within a structure called ICT centre. It's a requirement of both NUC and NAPTEB for accreditation of Tertiary institutions in Nigeria. Previous researches show that ICT units/departments are fully responsible for the procurement and deployment of solutions in the institutions. They also oversee the running and maintenance of the both the hardware and software computing needs of the entire campus community. Cloud Computing has been widely adopted by these institutions as shown in recent study, implying that many of these ICTs already have running, some form of cloud services.

The ICTs have routine services they offer at particular times of each academic sessions, example is the Admission Processes. This exercise takes so much resource of the ICTs more than any other exercise, even with the cloud subscriptions it is still a big issue. There are so much bottle necks in admission processes that in some institutions, students don't receive admission letters till $3^{\text {rd }}$ or $4^{\text {th }}$ year.

\section{The ICTs and Cloud Services}

Most institutions have Cloud subscription running. Recent studies show that these Cloud services are Public Cloud deployment models. Despite the emphasis to ensure that the right deployment and most suitable service delivery models along with reputable cloud service providers are chosen for a safe and reliable cloud, it is only natural that sometimes in some cases a lot of times failures will occur; hence, using the multi-cloud strategy is a better and more reliable way to handle failures. However, due to cost this is very rarely adopted because ICTs of most institutions could barely pay for their bandwidth subscription and are also grappling to pay for their existing Cloud subscription. Availability of services when it is needed is key to cloud adoption for most of the institutions until the issue of security became serious concern.

The Cloud service models range from Software as a Service (SaaS) to Platform as a Service (PaaS), which don't give any privilege of control over the institutions data. In some cases, this is even given out to contractors. Many of the Web Portals are designed and built and managed by contractors on behalf of the ICTs. In most cases, once there is change of management in the institution or disagreement with the contractor, it marks the end of that project.

Presently, most ICT centres under review have fairly good server rooms, housing some powerful servers which run most of the time at less than $25 \%$ of its 
capacity. There is so much waste of computing resources and power experienced on daily basis.

\subsection{Proposed New System}

This research proposes a scalable private cloud infrastructure that can enable tertiary institutions take full control of their data. This will among other things give the ICTs control over the institutions data, maximise server utilization, reduce complexity and ultimately decrease cost of ownership.

By combining the flexibility and reliability of server virtualization with the ease of management and provisioning of cloud computing, private cloud makes it much simpler for businesses to take advantage of enterprise applications in environments that are perfectly optimized for these critical services. And businesses today are embracing private cloud to a very high degree. Looking at the data from the recent 2015 survey on cloud computing and comparing it to that of 2013 survey, adoption of private cloud has more than doubled over the last two years, with over $70 \%$ of organizations having adopted it in some form [9] The architecture of an Onsite Private Cloud Infrastructure is shown in Figure 1.

\subsection{Framework for a Smooth Adoption and Deployment of a Private Cloud in ICTs}

A study by [3] have proposed a seven stage roadmap for the successful adoption of cloud in Nigerian Universities, mainly public cloud as discussed earlier. The roadmap the study proposed include; planning, choosing the right deployment model, choosing the most suitable service models, vendor selection, negotiating the SLA, migration, and integration.

Furthermore, some cloud architects have suggested different frameworks towards private Cloud deployment. In his work, Bob (2012), [10] proposed a ten stage approach. This research proposes a six stage framework for the implementation of Private cloud in the ICTs. The stages were first proposed by Saddharth J. (2011) [11] are: Planning and Assessment, Consolidation, Virtualization,

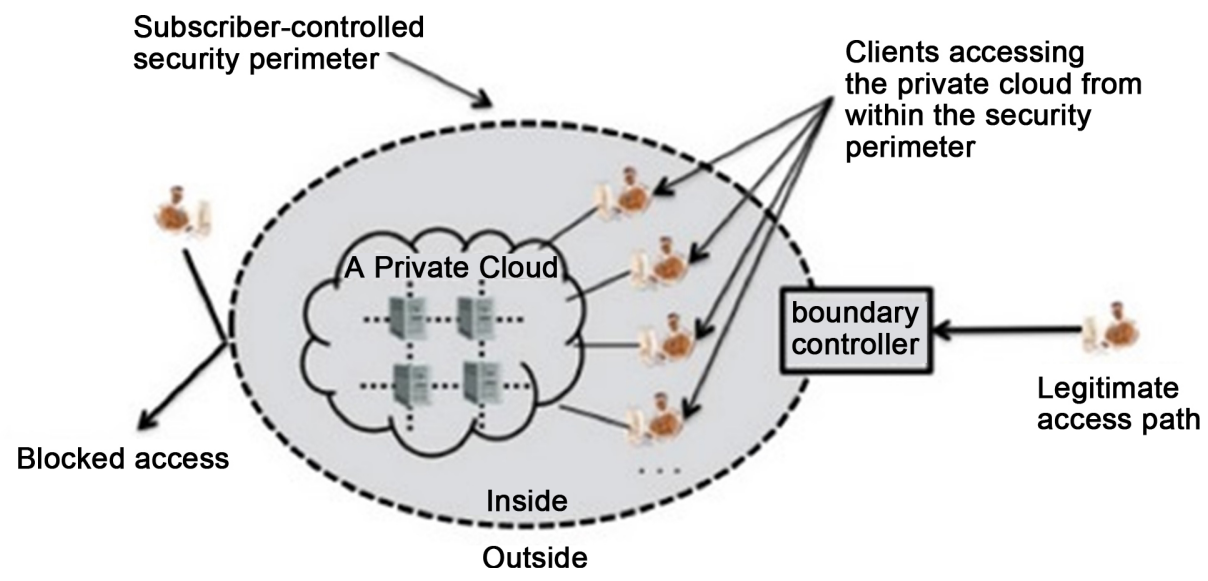

Source: Tecno-Pulse (2017).

Figure 1. Architecture of onsite private cloud. 


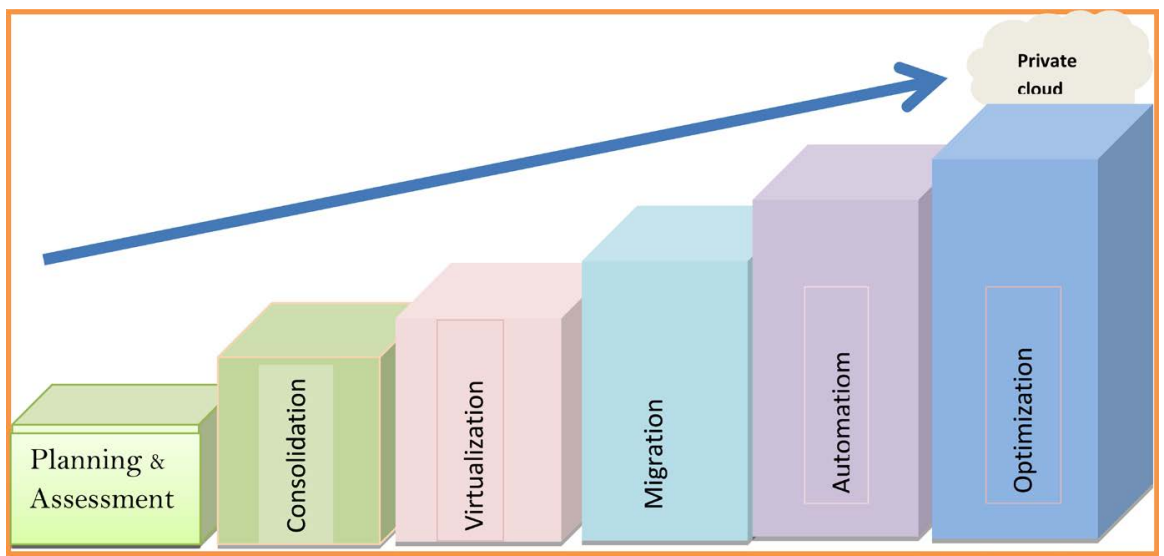

Source: Field work, 2017.

Figure 2. Framework for private cloud deployment in ICTs.

Migration, Automation and Optimization. Figure 2 shows the Framework for a Private Cloud Deployment in the ICT Centres of Tertiary Institutions.

\subsubsection{Planning and Assessment Stage}

The first step for an organization going in for a private cloud setup is planning and assessment. Here, the enterprise assesses existing infrastructure, people and other assets with respect to its IT portfolio. IT assets are benchmarked in terms of performance, availability and scalability, so that a cost-benefit analysis can be carried out based on the target cloud platform. An ROI model and a high-level strategy document should be prepared [11]. This is by far the most important stage in any cloud adoption, there should be a team, having the right people in place from the very beginning is necessary, because it will save a lot of costly mistakes from happening as the journey to the cloud continues [3].

\subsubsection{Consolidation}

The next step in private cloud setup is consolidation. All avenues for consolidation of IT infrastructure and budgets in the institution should be explored and implemented. For instance, if an organization has multiple data centres, like multiple campuses with each campus having its own ICT centre, it can consider discarding some of them. The institution should then consolidate the data in a central location to cater the requirements for the entire region. The central data centre must have cloud properties, so that it is robust enough to cater to all the data from different regions.

\subsubsection{Virtualization}

After consolidating IT assets, virtualization of IT infrastructure should be carefully done. This step in the private cloud setup journey will help optimize consolidated infrastructure. Generally, hardware sizing is done with a view to peak requirement/usage of that hardware. Institutions should ascertain the extent to which hardware is underutilized. For instance, if during assessment it is found that only $10 \%$ of the overall computing power is being utilized, then ways to 
utilize the remaining $90 \%$ of the capacity must be found. Here, virtualization solutions such as VMware, Xen hypervisor or Open Source solution could be used. Vendor specific Hypervisors are very much available in the market but they are very, very expensive. By doing this, the institution can maximize the usage of the IT infrastructure and exploit underutilized resources on the way to private cloud setup.

\subsubsection{Migration}

In migration, two key issues are raised. Application standardization-Once the infrastructure is virtualized and the ICT centre consolidated, consider application migration. Applications are assessed from a functional and non-functional perspective and accordingly selected or rejected for migration to the cloud. Application architecture standardization is an important factor. This involves building standard reference architecture, comparing it with the current application architecture, and establishing the gap between the two. Any anomalies have to be eliminated at this stage, modifying the applications as required, to conform to the reference cloud architecture.

Application performance-On a virtualized cloud platform there are certain qualities that are expected from applications. Let's assume the application accesses a file using a specific URL and a specific path. The cloud has no standard specific location of files because if the machine goes down, the file is lost and the application too goes down. On a cloud platform you cannot expect the application to access the file using a uniform path, when the same file can be located in multiple places on the cloud. Thus the application needs to be modified such that it doesn't expect the file to be in a specific location. The migration toward cloud should not be done all at once, as much as the cloud offers cost savings, increased agility and efficiency caution should be taken and the movement gradual with low risks applications going first [3].

\subsubsection{Automation}

The next step in the private cloud setup journey is automation, wherein qualities such as self-provisioning are incorporated in applications. For instance, if load on an application unexpectedly increases while it is running, a traditional environment would demand procurement of a new server, installation of the application and connection to the network, for the additional load to be handled. However in a private cloud setup, the application should have the self-scaling capacity to form a new virtual machine (VM), install itself in the virtual environment and commence servicing the new request.

Automation could also be carried out with respect to management and monitoring. In case a machine is down, an alert can go out automatically to the administrator. Ideally, without manual intervention, the cloud could create a new instance on its own and start the application as required. Automation built into applications thus enables self-healing and scaling. 


\subsubsection{Optimization}

The move to a private cloud setup is invariably prompted by potential cost and performance benefits. The final, optimization stage involves scrutiny of the metrics. After three months of running the applications on the private cloud setup, observe the metrics generated and evaluate whether targets are being met. Based on this analysis, modifications can be incorporated to attain the maximum benefit. This is the highest maturity level of the private cloud setup journey.

\section{Conclusion and Recommendation}

This paper presents a conceptual framework towards actualizing a private cloud infrastructure deployable in the ICT centres of the University and indeed other Tertiary institutions. The most critical stage is the Planning and assessment stage, getting the right team and adequate planning can make or mar the process of deploying an on-premises private cloud infrastructure. There are many vendors offering different flavours of private cloud deployments for different purposes, ICT centres are not IT organizations per say, there decisions are left for management to accept or not, more researches are needed to discuss how these private clouds offered by these vendors fit into the needs of the ICT centres and at what cost.

\section{Conflicts of Interest}

The authors declare no conflicts of interest regarding the publication of this paper.

\section{References}

[1] Yusuf, M.A., et al. (2013) Appraising the Role of Information Communication Technology (ICT) as a Change Agent for Higher Education in Nigeria. International Journal of Educational Administration and Policy Studies, 5, 177-183. http://www.academicjournals.org/IJEAPS

[2] Gartner Incorporation (2012) https://www.gartner.com/newsroom/id/1210613

[3] Safiya, O.U., et al. (2014) Cloud Computing Adoption Model for Universities to Increase ICT Proficiency. SAGE Journals, 4. https://doi.org/10.1177/2158244014546461

[4] Awosan, R.K. (2014) Factor Analysis of the Adoption of Cloud Computing in Nigeria. African Journal of Computing \& ICT, 7. http://www.ajocict.net

[5] Intel Incorporation (2012) Best Practices for Building an Enterprise Private Cloud. Intel. IT@Intel White Paper.

https://www.intel.com/content/www/us/en/it-management/intel-it/intel-it-best-pra ctices.html

[6] Zhang, Q., et al. (2010) Cloud Computing: State-of-the-Art and Research Challenges. Brazilian Computer Society. https://u.cs.biu.ac.il/ ariel/download/ds590/resources

[7] Obunadike, G.N., et al. (2014) A Phase Approach for Adopting Private Clouds as a Collaborative Platform for Nigerian Universities. http://www.iiste.org/Journals/index.php/IKM/article/view/15652

[8] Saidhbi, S. (2013) A Cloud Computing Model for Ethiopian Higher Institutions 
IOSR. Journal of Computer Engineering (IOSRJCE), 6, 1-9.

http://www.iosrjournals.org/

[9] Aberdeen Group (2015) A Simple Path to Private Cloud White Paper. https://ww.aberdeen.com/

[10] Plankers, B. (2012) Handbook on Building a Private Cloud in Ten Steps Virtualization and Cloud Architect.

[11] Jaiswar, S. (SCEA) (2011) Private Cloud Setup in Six Steps. Sun Certified Enterprise Architect. https://www.computerweekly.com/ 